\section{Maternal and perinatal outcomes of uterine rupture in Lubumbashi, Democratic Republic of Congo}

\author{
Jacques Ngoy Kitenge ${ }^{1}$, Olivier Mukuku², Xavier K \\ Kinenkinda ${ }^{1}$ and Prosper L Kakudji ${ }^{1}$ \\ 1Department of Gynecology and Obstetrics, Faculty of Medicine, University of Lubumbashi, \\ Lubumbashi, Democratic Republic of Congo \\ ${ }^{2}$ Higher Institute of Medical Techniques, Lubumbashi, Democratic Republic of Congo
}

\section{Abstract}

Introduction: Uterine rupture is one of the peripartum complications, which cause nearly about one out of thirteen maternal deaths. This study aimed to assess the prevalence and associated factors of mortality among women with uterine rupture in referral hospitals of Lubumbashi, in the south east part of the Democratic Republic of Congo.

Methods: Institution based cross sectional study was conducted from December $1^{\text {st }}, 2012$ to $31^{\text {st }}, 2016$ on uterine rupture. During the study selected 158 women were included by using exhaustive sampling method. Data were checked, coded and analyzed into STATA version 12. Chi-square test was used to identify the predictors of maternal and perinatal mortalities in women with uterine rupture and $95 \%$ Confidence Interval of odds ratio at $p$ - value less than 0.05 was taken as a significance level.

Results: The overall prevalence of uterine rupture was $0.49 \%$. The average age of the patients was $29.5 \pm 6.2$ years and $71.52 \%$ of them were between 20 and 34 years old; more than $60 \%$ had a parity $\geq 4$ (average parity: $4.7 \pm 2.5$ ). $81.17 \%$ of the cases had a fully ruptured uterus and $51.17 \%$ of the uterine ruptures were located in the lower segment. Repair of the pregnant ruptured uterus was performed in $93.04 \%$ of the cases and hysterectomy in $5.06 \%$. Maternal and perinatal mortalities were $8.86 \%$ and $72.04 \%$ respectively. Regarding maternal mortality, no parameter showed a significant association with maternal death. As for perinatal mortality, parity $\geq 4$, complete rupture and segmento-corporeal lesion were significantly associated with perinatal death $(p<0.05)$.

Conclusion: Uterine rupture remains one of the causes of maternal and perinatal mortality in Lubumbashi. The place occupied by uterine ruptures in obstetric activity requires joint and urgent action by all stakeholders in the health system in order to combat this scourge, witness to poor quality obstetric care.

\section{More Information}

*Address for Correspondence:

Dr. Olivier Mukuku, Higher Institute of Medical Techniques, Lubumbashi, Democratic Republic of Congo, Tel: +243997925 649;

Email: oliviermukuku@yahoo.fr

Subm itted: 27 August 2020

Approved: 19 October 2020

Published: 20 October 2020

How to cite this article: Kitenge JN, Mukuku O, Kinenkinda XK, Kakudji PL. Maternal and perinatal outcomes of uterine rupture in Lubumbashi, Democratic Republic of Congo. Clin J Obstet Gynecol. 2020; 3: 136-141.

DOI: 10.29328/journal.cjog.1001067

Copyright: (c 2020 Kitenge JN, et al. This is an open access article distributed under the Creative Commons Attribution License, which permits unrestricted use, distribution, and reproduction in any medium, provided the original work is properly cited.

Keywords: Uterine rupture; Prevalence; Mortality; Lubumbashi

Check for updates

OPEN ACCESS

\section{Introduction}

Uterine rupture is defined as a non-surgical continuity solution of the pregnant uterus reaching the uterine fundus and/ or the lower segment. It can be spontaneous or provoked [1]. It occurs most often during labor, but it can also occur during pregnancy, on a healthy or scarred uterus. Anatomically, there are two forms of uterine rupture: complete rupture (or intraperitoneal rupture) and incomplete rupture (or disunity when it occurs on a scar uterus) [1]. The frequency of the occurrence of uterine rupture varies in different regions of the world. It is rare in developed countries but remains a public health problem in developing countries, particularly in Africa where it occurs mainly as a result of prolonged or obstructed labor [2,3]. Uterine rupture is one of the major obstetric complications that contribute significantly to maternal and perinatal mortality and morbidity [2], especially in our underequipped countries where accessibility to quality health care is a problem. Its prevalence in Africa is between 0.3 and $2.4 \%$ $[2,4]$ while in Europe and industrialized countries in general it is below $0.1 \%[5,6]$. The majority of the cases in these countries occur in women with a history of cesarean section while in developing countries it is rather prolonged labor on non-scarred uterus [2,7]. In the Democratic Republic of Congo (DRC), in Lubumbashi, Kakudji, et al. [8] reported 12 (0.41\%) 
cases of uterine rupture out of a total of 2,911 deliveries recorded in 10 reference maternities. Mwilenyi, et al. [9], in their study at Jason Sendwe Hospital in Lubumbashi, found a frequency of $1.1 \%$ and the maternal and perinatal mortalities were $15.1 \%$ and $76.1 \%$ respectively.

However, there are very few studies on this subject in DRC despite the observation made about the existence of this pathology and its consequences in our obstetric practice. In view of the situation described above, it is imperative to know the situation in our country and particularly in Lubumbashi city.

This study aimed to assess the prevalence and associated factors of mortality among women with uterine rupture in referral hospitals of Lubumbashi, in the south east part of the Democratic Republic of Congo.

\section{Materials and methods}

\section{Study setting}

The study setting was Lubumbashi city, which is located in the south east part of the Democratic Republic of Congo. We selected 9 public referral maternities funded by Government of DRC through the Ministry of Health. (Provincial General Reference Hospital Jason Sendwe, University Clinics, Gécamines-Sud Hospital, SNCC Hospital, General Reference Hospital of Katuba, General Reference Hospital of Kamalondo, General Reference Hospital of Kampemba, General Hospital Reference of Rwashi and General Reference Hospital of Kenya). Lubumbashi is a city with a population of more than 2 million people.

Institution based cross sectional study was conducted from December $1^{\text {st }}, 2012$ to $31^{\text {st }}, 2016$ on uterine rupture.

\section{Case definition and selection}

Uterine rupture was defined as tearing of the uterine wall either partially or complete during pregnancy and labor, diagnosed either clinically and later confirmed at laparotomy. The cases were retrospectively collected from the maternity ward and operating theatre registers as well as from the patients' case files at the hospital medical records office.

In total, we included by using exhaustive sampling method 186 cases of uterine rupture which allowed us to calculate the frequency. But of the 186 cases, we excluded 28 cases in the statistical analyzes due to an incomplete record missing most of the study variables.

\section{Data collection}

Data was abstracted from the maternity ward and operating theatre registers as well as from the patients' case files at the hospital medical records office using a pre tested case report form. Information on the patients' age, parity, previous caesarean section, antenatal care attendance, modality of admission at the hospital, gestational age, type of uterine rupture, site of uterine rupture, type of treatment, maternal and fetal outcomes, length of postoperative hospital stay and other relevant information were collected.

The data collectors were midwives who were trained to collect data from women's obstetric files or charts and to validate the diagnosis of obstructed labor using admission, delivery and theatre registers. Thought the data collection period which lasted 4 weeks, the first author was providing oversight and supervision to prevent under reporting.

\section{Statistical analysis}

The data were entered and analyzed using STATA software, version 12.0. Descriptive statistics were obtained through frequencies and cross tabulations. Chi square test or Fisher exact test when appropriate were used to identify the predictors of maternal and perinatal mortalities in women with uterine rupture and 95\% Confidence Interval (95\% CI) of odds ratio (OR) at p-value less than 0.05 was taken as a significance level.

\section{Ethical considerations}

Ethical approval was obtained from the Ethical Medical Committee of the University of Lubumbashi. Permission to access obstetric records was obtained from the medical director of the hospital and these were anonymously entered into the database.

\section{Results}

Among the 37,641 deliveries carried out during this period, we identified 186 cases of uterine rupture, i.e. a prevalence of 0.49\% (95\% CI: 0.42 - 0.57\%).

The ages of mothers who got uterine rupture ranged between 15-44 years, with an average age of $29.5 \pm 6.2$ years. The average parity was $4.7 \pm 2.5$ with (range: from 1 to 11 ). Most of the cases 132 (83.54\%) were referred from peripheral maternities, and 57 (36.06\%) mothers had not performed any antenatal care (ANC) visit. The major part of uterine ruptures had occurred in term pregnancies (82.17\%). The average gestational age was $38.23 \pm 2.65$ weeks (range: from 28 to 42 weeks).

Sixty-eight (43.04\%) cases had occurred on a scarred uterus (history of the previous caesarean section) and 90 $(56.96 \%)$ cases on a healthy uterus.

The rupture site was essentially the lower segment in $51.27 \%$ of the cases, and the rupture was complete in $81.17 \%$ and incomplete in $18.83 \%$.

All women received a blood transfusion and surgical treatment. Repair of the ruptured uterus was performed in 147 (93.04\%) mothers; 8 (5.06\%) underwent an emergency obstetric hysterectomy (Table 1). The average length of 
hospital stay was 15.6 days (ranges: from 1 to 36 days). We recorded 14 cases of maternal death, i.e a mortality rate of $8.86 \%$. These maternal deaths occurred following a hemorrhagic shock, including 3 preoperatively. Nineteen (15.82\%) newborns weighed $\geq 4000$ grams and 115 (68.99\%) between 2500 and 3999 grams. One hundred sixteen 116 (72.04\%) newborns died in perinatal period and 45 (27.96\%) survived.

No parameter studied was associated with maternal death (Table 2). As for perinatal death (Table 3), we found that parity $\geq 4$ was significantly associated with perinatal death, indicating that newborns of mothers with parity $\geq 4$ had 3.5 times the risk of dying compared to those of mothers having a parity $<4(\mathrm{OR}=3.5$ [1.7-7.2]). Similarly, for newborns of mothers who had a complete rupture, they were 13.9 times more likely to die compared to those whose mothers had an incomplete rupture $(\mathrm{OR}=13.9$ [5.3-36.5]). As for the site of the rupture, the segmento-corporeal lesion was significantly associated with perinatal death $(\mathrm{OR}=6.4$ [1.9-21.3]).

\section{Discussion}

\section{Prevalence}

The frequency of uterine rupture varies according to hospital statistics. We recorded an overall prevalence of $0.49 \%$. This frequency is comparable to that recently reported

Table 1: Types of operations done.

\begin{tabular}{|c|c|c|}
\hline Operation procedure & Number & Percentage \\
\hline Repair of the uterus & 147 & 93.04 \\
\hline Total abdominal hysterectomy & 8 & 5.06 \\
\hline None & 3 & 1.90 \\
\hline Total & 158 & 100 \\
\hline
\end{tabular}

in Lubumbashi (DRC) by Kakudji, et al. [8] which was $0.41 \%$. It seems to be higher than that reported in 1994 in Nyankunde (in the north east part of the DRC) by Ahuka, et al. (0.35\%) [10].

In the literature review, we found that the prevalence of uterine rupture in African countries varied between $0.29 \%$ and $2.44 \%$ [4,11-15], and those found in Asian countries, varying between $0.2 \%$ and $1.6 \%$ [3,16-19]. These frequencies recorded in African and Asian countries are much higher than those observed in the European continent where frequencies were lower than $0.1 \%[5,6,20]$, and that observed in Australia where it was $0.17 \%$ [21].

We think that these frequencies reported in African countries could be underestimated because few studies have been carried out in rural areas (where home deliveries have so far been noted), and most of the data come from urban centers, where the incidence of uterine rupture may be lower because services are more easily accessible [22].

This high frequency of uterine ruptures in developing countries is probably linked to lack of equipment, low number of qualified and trained caregivers in obstetric and neonatal emergency care in maternities and high number of makeshift maternities (where diagnosis, management and timely referral of obstetric emergencies remain a serious problem) which are constantly emerging in some large African cities. To these are added the problem of lack of ANC visits in our settings where less than $30 \%$ of pregnant women reach 4 or more ANC $[8,23]$.

\section{Type and site of the uterine rupture}

In our study, $81.17 \%$ of uterine ruptures were complete

Table 2: Factors associated with maternal mortality in uterine rupture.

\begin{tabular}{|c|c|c|c|c|c|c|c|}
\hline \multirow{3}{*}{ Variable } & \multirow{3}{*}{$\begin{array}{c}\text { Total }(n=158) \\
\text { N }\end{array}$} & \multicolumn{4}{|c|}{ Maternal outcome } & \multirow{3}{*}{ OR $[95 \% \mathrm{Cl}]$} & \multirow{3}{*}{$p$ - value } \\
\hline & & \multicolumn{2}{|c|}{ Died $(n=14)$} & \multicolumn{2}{|c|}{ Survived $(n=144)$} & & \\
\hline & & $n$ & $\%$ & $n$ & $\%$ & & \\
\hline \multicolumn{8}{|l|}{ Age } \\
\hline$<35$ years & 125 & 10 & 8.0 & 115 & 92.0 & 1.0 & \\
\hline$\geq 35$ years & 33 & 4 & 12.1 & 29 & 87.9 & $1.6[0.4-5.4]$ & 0.6916 \\
\hline \multicolumn{8}{|l|}{ Parity } \\
\hline$<4$ & 64 & 4 & 6.3 & 60 & 93.7 & 1.0 & \\
\hline$\geq 4$ & 94 & 10 & 10.6 & 84 & 89.4 & $1.8[0.5-8.1]$ & 0.5043 \\
\hline \multicolumn{8}{|l|}{ Referral } \\
\hline Yes & 132 & 13 & 9.9 & 119 & 90.1 & $2.7[0.3-21.8]$ & 0.5439 \\
\hline No & 26 & 1 & 3.8 & 25 & 96.2 & 1.0 & \\
\hline \multicolumn{8}{|c|}{ Previous caesarean section } \\
\hline Yes & 90 & 11 & 12.2 & 79 & 87.8 & $3.0[0.8-11.3]$ & 0.1533 \\
\hline No & 68 & 3 & 4.4 & 65 & 95.6 & 1.0 & \\
\hline \multicolumn{8}{|l|}{ Attended antenatal care } \\
\hline Yes & 101 & 6 & 5.9 & 95 & 94.1 & 1.0 & \\
\hline No & 57 & 8 & 14.0 & 49 & 86.0 & $2.6[0.8-7.9]$ & 0.1533 \\
\hline \multicolumn{8}{|c|}{ Rupture based on the extent } \\
\hline Incomplete & 29 & 1 & 3.5 & 28 & 96.5 & 1.0 & \\
\hline Complete & 125 & 13 & 10.4 & 112 & 89.6 & $3.3[0.4-25.9]$ & 0.4152 \\
\hline \multicolumn{8}{|l|}{ Site of the uterine rupture } \\
\hline Lower segment & 81 & 7 & 80.5 & 74 & 19.5 & 1.0 & \\
\hline Segmento-corporeal & 60 & 7 & 11.7 & 53 & 88.3 & $1.4[0.5-4.2]$ & 0.7573 \\
\hline Fundus & 16 & 0 & 0.0 & 16 & 100.0 & $0.0[0.0-3.5]$ & 0.5957 \\
\hline
\end{tabular}




\begin{tabular}{|c|c|c|c|c|c|c|c|}
\hline \multirow{3}{*}{ Variable } & \multirow{3}{*}{$\begin{array}{c}\text { Total }(\mathrm{N}=158) \\
\mathrm{N}\end{array}$} & \multicolumn{4}{|c|}{ Perinatal outcome } & \multirow{3}{*}{ OR $[95 \% \mathrm{Cl}]$} & \multirow{3}{*}{$p$ - value } \\
\hline & & \multicolumn{2}{|c|}{ Died $(n=113)$} & \multicolumn{2}{|c|}{ Survived $(n=45)$} & & \\
\hline & & $n$ & $\%$ & $n$ & $\%$ & & \\
\hline \multicolumn{8}{|l|}{ Age } \\
\hline$<35$ years & 125 & 88 & 70.4 & 37 & 29.6 & 1.0 & \\
\hline$\geq 35$ years & 33 & 25 & 75.8 & 8 & 24.2 & $1.3[0.5-3.2]$ & 0.6967 \\
\hline \multicolumn{8}{|l|}{ Parity } \\
\hline$<4$ & 64 & 36 & 56.3 & 28 & 43.7 & 1.0 & \\
\hline$\geq 4$ & 94 & 77 & 81.9 & 17 & 18.1 & $3.5[1.7-7.2]$ & 0.0008 \\
\hline \multicolumn{8}{|l|}{ Referral } \\
\hline Yes & 132 & 98 & 74.2 & 34 & 25.8 & $2.1[0.9-5.0]$ & 0.1411 \\
\hline No & 26 & 15 & 57.7 & 11 & 42.3 & 1.0 & \\
\hline \multicolumn{8}{|l|}{ Previous caesarean section } \\
\hline Yes & 90 & 64 & 71.1 & 26 & 28.9 & 1.0 & \\
\hline No & 68 & 49 & 72.1 & 19 & 27.9 & $1.0[0.5-2.1]$ & 1.000 \\
\hline \multicolumn{8}{|l|}{ Attended antenatal care } \\
\hline No & 57 & 43 & 79.8 & 14 & 20.2 & 1.0 & \\
\hline Yes & 101 & 70 & 94.4 & 31 & 5.6 & $0.7[0.4-1.5]$ & 0.5244 \\
\hline \multicolumn{8}{|c|}{ Rupture based on the extent } \\
\hline Complete & 125 & 102 & 85.1 & 23 & 14.9 & $13.9[5.3-36.5]$ & $<0.0001$ \\
\hline Incomplete & 29 & 7 & 24.1 & 22 & 75.9 & 1.0 & \\
\hline \multicolumn{8}{|l|}{ Site of the uterine rupture } \\
\hline Lower segment & 81 & 56 & 80.5 & 25 & 19.5 & $2.9[0.96-8.6]$ & 0.0973 \\
\hline Segmento-Corporeal & 60 & 50 & 93.6 & 10 & 6.4 & $6.4[1.9-21.3]$ & 0.003 \\
\hline Fundus & 16 & 7 & 43.8 & 9 & 56.2 & 1.0 & \\
\hline \multicolumn{8}{|l|}{ Gestational age } \\
\hline Preterm & 28 & 22 & 78.6 & 6 & 21.4 & $1.6[0.6-4.2]$ & 0.4818 \\
\hline Term & 129 & 90 & 69.8 & 39 & 30.2 & 1.0 & \\
\hline \multicolumn{8}{|l|}{ Fetal weight } \\
\hline$<2500$ grams & 24 & 18 & 75.0 & 6 & 25.0 & $1.3[0.5-3.6]$ & 0.7756 \\
\hline 2500-3999 grams & 115 & 80 & 69.6 & 35 & 30.4 & 1.0 & \\
\hline$\geq 4000$ grams & 19 & 15 & 79.0 & 4 & 21.0 & $16[0.6-5.3]$ & 0.5744 \\
\hline
\end{tabular}

and $18.83 \%$ were incomplete. This predominance of complete uterine ruptures over incomplete ones is also found in several studies $[3,4,24,25]$. Contrary to our observation, Guyot, et al. [7] (in France) found a higher proportion of incomplete ruptures $(69.44 \%)$ than complete ruptures.

We noted that in only $10 \%$ of the cases did the uterine rupture sit in the fundus; $51 \%$ had involved the lower segment alone and nearly $38 \%$ of the uterine ruptures were segmentocorporeal. Kouakou, et al. [26], Astatikie, et al. [4] and Diallo, et al. [14] found that many uterine ruptures were located in the lower segment with $77.48 \%, 71.5 \%$ and $70.41 \%$ of the cases, respectively.

Fouedjio, et al. [24] had found 50\% of segmento-corporeal lesions. In these segmento-corporeal lesions, the uterine breach would certainly have started in the lower segment and would have spread to the uterine fundus because of the delay in management. Because of its fragility, it is the lower segment which is the choice's site for rupture, thus constituting the starting point for most uterine ruptures [6]. Also, we must add the important role of low segment caesarean section as provider of segmental and segmento-corporeal ruptures. Corporeal ruptures are often secondary to corporeal caesarean sections which are rare, but also to myomectomies.

\section{Management}

Repair of the ruptured uterus (conservative surgery) was the most common (93.04\%) in our series; it was performed whenever state of the uterus, site and extent of lesions had permitted it. This conservative tendency is found in several studies from African countries [14,27,28] because the procreative function is an important element in the balance of African households [14].

In our series the proportion of hysterectomy was 5.06\%. Guyot, et al. [7] had not reported any hemostasis hysterectomy in their series. The rate of hemostasis hysterectomies varies in the literature between 5.6 and $61.5 \%$ in the event of complete ruptures [6,14,29-32]. Mukasa, et al. [2], in their series of 83 Ugandan women, recorded $28.6 \%$ total hysterectomy and $37.7 \%$ subtotal hysterectomy. Astatikie, et al. [4], in their series of 242 Ethiopian women, reported $73.9 \%$ hysterectomy ( $57 \%$ total hysterectomy and $16.9 \%$ subtotal hysterectomy). These not very homogeneous rates seem to be linked to the difference in attitude adopted taking into account certain parameters, namely age, parity, extent of lesions, involvement of vascular pedicles, state of the uterine muscle, desire of the patient's subsequent pregnancy and presence or absence of infection.

\section{Maternal outcome}

Out of 158 cases of uterine rupture, we observed 14 (8.86\%) maternal deaths or approximately one death for 11 cases of uterine rupture. This result could be explained by 
the delay in referral women from the first level health centers to the reference hospitals and also by the delay in diagnosis and treatment. Nayama, et al. [31], in their series of 195 Niger women, no maternal death was recorded. The literature review shows that the maternal mortality found in African countries varies between 4.8 and $21.4 \%[11,12,14,27]$, and between 5 and $12.5 \%$ in Asian countries [3,16,17-25]. It is still largely extended to that observed in the United States, which is $0.29 \%$ [33], to that observed in Europe, which is less than $1.5 \%[5,7,20,34,35]$.

Our study shows that none of the variables studied were associated with maternal death. Eze and Ibekwe noted that the maternal deaths recorded in their study were due to hypovolaemia secondary to massive hemorrhage and septicemia [27]. Astatikie, et al. [4] found that women whose birthing was done at home, those who developed hypovolemic shock or severe postoperative anemia were more likely to die from the uterine rupture. For Ahmed, et al. [30], maternal death was significantly associated with duration of surgery greater than 2 hours and they pointed out that this would be attributed to the complexity of the uterine lesion and the poor general condition of the patient. As Ahmed, et al [30], we believe that early admission of pregnant women to hospital, timely diagnosis of uterine rupture, adequate resuscitation of patients, availability of a blood transfusion, short delay between diagnosis and management as well as presence of an experienced surgeon have a reducing effect on maternal death after uterine rupture. Osemwenkha and Osaikhuwuomwan [36] emphasize that late admission to the hospital is a major cause of this poor outcome and is due to poverty, delays in referral, poor transport network and lack of ambulance services.

\section{Perinatal outcome}

Perinatal death rate in our study was $72.04 \%$. The feticidal nature of uterine ruptures had been found in numerous African studies where the perinatal mortality linked to uterine rupture varied between $61.29 \%$ and $98 \%$ [4,13,36-38]. These figures are comparable to those found in Asian countries where it varies between $61.90 \%$ and $87.50 \%$ [25]. It is very much higher than that observed in Europe, varying between $0 \%$ and $15.72 \%[7,34,35]$, and in the United States where it is $1,44 \%$ [33].

In our study, complete and segmento-corporeal uterine lesions were significantly associated with perinatal death. This could be explained by the fact that these lesions would be more hemorrhagic and therefore likely to quickly cause death of the newborn because maternal antepartum hemorrhage is a risk factor for perinatal death. The delay in diagnosis and management (most of patients being admitted after rupture) and an under-equipped neonatal resuscitation structure are believed to be the cause of this high rate of stillbirths in developing countries.

\section{Conclusion}

Uterine rupture is a devastating condition that carries grave risks to the newborn and the mother as well. Uterine rupture is an obstetric condition with catastrophic consequences. The resulting high perinatal mortality suggests a synergy of action between political decision-makers, health caregivers and the community itself to promote antenatal care, family planning, to improve the health system through periodic refresher courses. Likewise, the provision of medical transport at each health center is necessary to speed up medical referrals, in order to eliminate delays in management.

\section{References}

1. Marpeau L, Lansac J, Teurnier F. Traité d'Obstétrique. Paris: Masson. 2010.

2. Mukasa P, Kabakyenga J, Senkungu JK, Ngozi J, Kyalimpa M, et al Uterine rupture in a teaching hospital in Mbarara, western Uganda, unmatched case-control study. Reprod Health. 2013; 10: 29.

3. Aziz N, Yousfani S. Analysis of uterine rupture at university teaching hospital Pakistan. Pak J Med Sci. 2015; 31: 920-924.

PubMed: https://www.ncbi.nlm.nih.gov/pmc/articles/PMC4590369/

4. Astatikie G, Limenih MA, Kebede M. Maternal and fetal outcomes of uterine rupture and factors associated with maternal death secondary to uterine rupture. BMC Pregnancy and Childbirth. 2017; 17: 117. PubMed: https://pubmed.ncbi.nlm.nih.gov/28403833/

5. Zwart JJ, Richters JM, Ory F, De Vries JI, Blomenkamp KW, et al Uterine rupture in the Nethrlands: a nationwide population-based cohort study. BJOG. 2009; 116: 1069-1078.

PubMed: https://pubmed.ncbi.nlm.nih.gov/19515148/

6. Ofir K, Sheiner E, Levy A, Katz M, Mazor M. Uterine rupture: risk factors and pregnancy outcome. Am J Obstet Gynecol. 2003; 189: 1042-1046. PubMed: https://pubmed.ncbi.nlm.nih.gov/14586352/

7. Guyot A, Carbonnel M, Frey C, Pharisien I, Uzan M, et al. Rupture utérine: facteurs de risque, complications maternelles et fœtales. Journal de Gynécologie Obstétrique et Biologie de la Reproduction. 2010; 39: 238-245.

8. Kakudji YK, Nsambi JB, Mukuku O, Tandu-Umba B, Kakudji PL. Profile of delivering mothers in Lubumbashi, Democratic Republic of Congo. Afr J Health Issues. 2017; $1: 3$.

9. Mwilenyi K. Etude de la rupture utérine à l'Hôpital Jason Sendwe de Lubumbashi. Kisangani Médical. 2015; 6.

10. Ahuka OL, Lusi KM, Nickson $P$. Obstetric uterine ruptures in a rural area in Zaire. Tropical Doctor. 1994; 24: 90-93.

PubMed: https://pubmed.ncbi.nlm.nih.gov/8009636/

11. Adegbola $\mathrm{O}$, Odeseye AK. Uterine rupture at Lagos University Teaching Hospital. J ClinSci. 2017; 14: 13-17.

12. Ngbale RN, Gaunefet CE, Koirokpi A, et al. Evolution des ruptures utérines à la maternité' de l'hôpital communautaire de Bangui. Med Afr Noire. 2012; 59: 65-69.

13. Rajaonarison JJC, Fenomanana MS, Rakotondraisoa JM, Randriambelomanana JA. Rupture utérine pendant le travail: facteurs étiologiques et pronostic materno-fœtal. Revue d'AnesthésieRéanimation et de Médecine d'Urgence. 2014; 6: 8-12.

14. Diallo MH, Baldé IS, Mamy MN, Diallo BS, Baldé O, Barry AB, Keita N. Rupture utérine: aspects sociodémographique, étiologique et prise en charge à la clinique universitaire de gynécologie et d'obstétrique de I'hôpital national Donka, CHU de Conakry, Guinée. Med Sante Trop. 2017; 27: 305-309. 
15. Yemane Y, Gizaw W. Assessment of the Associated Factors, Management and Complications of Uterine Rupture at Mizan-Tepi University Teaching Hospital, Mizan-Aman Town, Bench-Maji Zone, Snnprs, South West Ethiopia, 2016/17: A Case Control Study. Health Sci J. 2017; 11.

16. Qazi Q, Akhtar Z, Khan K, Khan AH. Woman health; uterus rupture, its complications and management in teaching hospital bannu, Pakistan. Mædica. 2012; 7: 49-53.

PubMed: https://www.ncbi.nlm.nih.gov/pmc/articles/PMC3484796/

17. Yalda MA, Munib A. Uterine rupture in Dohuk, Iraq. East Mediterr Health J. 2009; 15: 1272-1277.

18. Chuni N. Analysis of uterine rupture in a tertiary center in Eastern Nepal: lessons for obstetric care. J Obstetr Gynaecol Res. 2006; 32 574-579.

PubMed: https://pubmed.ncbi.nlm.nih.gov/17100819/

19. Veena P, Habeebullah S, Chaturvedula L. A review of 93 cases of ruptured uterus over a period of 2 years in a tertiary care hospital in South India. J Obstetr Gynaecol. 2012; 32: 260-263.

PubMed: https://pubmed.ncbi.nlm.nih.gov/22369400/

20. Vandenberghe G, De Blaere M, Van Leeuw V, Roelens K, Englert $Y$, et al. Nationwide population-based cohort study of uterine rupture in Belgium: results from the Belgian Obstetric Surveillance System. BMJ Open. 2016; 6: e010415.

21. Dekker GA, Chan A, Luke CG, Priest K, Riley M, et al. Risk of uterine rupture in Australian women attempting vaginal birth after one prior caesarean section: a retrospective population-based cohort study. BJOG. 2010; 117: 1358-1365.

PubMed: https://pubmed.ncbi.nlm.nih.gov/20716251/

22. Van Den Akker T, Mwagomba B, Irlam J, van Roosmalen J. Using audits to reduce the incidence of uterine rupture in a Malawian district hospital. Int J Gynecol Obstetr. 2009; 107: 289-294. PubMed: https://pubmed.ncbi.nlm.nih.gov/19846089/

23. Maleya A, Kakudji YK, Munan RM, Nsambi JB, Ngwej HI, et al. Issues materno-fœtales des grossesses non suivies à Lubumbashi, République Démocratique du Congo. The Pan African Med J. 2019; 33: 66. PubMed: https://www.ncbi.nlm.nih.gov/pmc/articles/PMC6689857/

24. Fouedjio JH, Ngo DingomMadye A, FouelifackYmélé F, FouogueTsuala J. Les Ruptures Utérines dans Deux Hôpitaux Universitaires de la Ville de Yaoundé : Aspects cliniques et Thérapeutiques. Health Sci Dis 2016; 17: 36-40.

25. Khooharo $\mathrm{Y}$, Yousfani JZ, Malik SH, Amber A, Majeed N, et al. Incidence and management of rupture uterus in obstructed labor. J Ayub Med Coll Abbottabad. 2013; 25: 149-151.

PubMed: https://pubmed.ncbi.nlm.nih.gov/25098081/

26. Kouakou P, Djanhan Y, Doumbia Y, Djanhan L, Outtara M. Les ruptures utérines : aspects épidémiologiques et pronostic fœto-maternel à la maternité du CHU de Bouaké (Côte d'Ivoire). Rev CAMES. 2007; A: 87-91.
27. Eze JN, Ibekwe PC. Uterine rupture at a secondary hospital in Afikpo, Southeast Nigeria. Singapore Med J. 2010; 51: 506-511. PubMed: https://pubmed.ncbi.nlm.nih.gov/20658112/

28. Rabarikoto HF, Randriamahavonjy $R$, Randriantoanina FE, Ravelosoa E, Samison LH, et al. Les ruptures utérines au cours du travail, observées au CHUA/GOB Antananarivo Madagascar. Revue d'Anesthésie-Réanimation et de Médecine d'urgence. 2010; 2: 5-7.

29. Kwee $A B$, Visser MG. Uterine rupture and its complications in the Netherlands: a prospective study. Eur J Obstet Gynecol Reprod Biol. 2006; 128: 257-261.

PubMed: https://pubmed.ncbi.nlm.nih.gov/16530918/

30. Ahmed DM, Mengistu TS, Endalamaw AG. Incidence and factors associated with outcomes of uterine rupture among women delivered at Felegehiwot referral hospital, Bahir Dar, Ethiopia: cross sectional study. BMC Pregnancy and Childbirth. 2018; 18: 447 PubMed: https://pubmed.ncbi.nlm.nih.gov/30445936/

31. Nayama M, Mohamed-Alzouma I, Garba M, Idi N, Oumara M, et al Ruptures utérines obstétricales à la maternité Issaka Gazoby de Niamey. A propos d'une étude rétrospective de 195 cas sur 3 ans. Médecine d'Afrique Noire. 2015; 62: 49-55.

32. Kieser KE, Baskett TF. A 10-year population-based study of uterine rupture Obstet Gynecol. 2002; 100: 749-753. PubMed: https://pubmed.ncbi.nlm.nih.gov/12383544/

33. Barger MK, Nannini A, Weiss J, Declercq ER, Stubblefield P, et al. Severe maternal and perinatal outcomes from uterine rupture among women at term with a trial of labor. J Perinatol. 2012; 32: 837-843. PubMed: https://pubmed.ncbi.nlm.nih.gov/22441115/

34. Kaczmarczyk M, Sparén $P$, Terry $P$, Cnattingius $S$. Risk factors for uterine rupture and neonatal consequences of uterine rupture: a population-based study of successive pregnancies in Sweden. BJOG. 2007; 114: 1208-1214.

PubMed: https://pubmed.ncbi.nlm.nih.gov/17877673/

35. Fitzpatrick KE, Kurinczuk JJ, Alfirevic $Z$, Spark $P$, Brocklehurst $P$, et al. Uterine rupture by intended mode delivery in the UK: a national case-control study. PLoS Med. 2012; 9: e1001184. PubMed: https://pubmed.ncbi.nlm.nih.gov/22427745/

36. Osemwenkha PA, Osaikhuwuomwan JA. A 10-year review of uterine rupture and its outcome in the University of Benin Teaching Hospital, Benin City. Niger J Surg Sci. 2016; 26: 1-4.

37. Mbamara SU, Obiechina NJA, Eleje GU. An analysis of uterine rupture at the Nnamdi Azikiwe University Teaching Hospital Nnewi, Southeast Nigeria. Niger J Clin Pract. 2012; 15: 448-445.

PubMed: https://pubmed.ncbi.nlm.nih.gov/23238196/

38. Gessessew A, Mengiste MM. Ruptured uterus - Eight year retrospective analysis of causes and management outcome in Adigrat Hospital, Tigray region. Ethiop J Health Dev. 2002; 16: 241-245. 